\title{
Um novo olhar para a resolução de conflitos educacionais - Processos construtivos por meio da mediação escolar
}

\author{
A new look at the resolution of educational conflicts - Constructive processes through school \\ mediation
}

Una nueva mirada a la resolución de conflictos educativos: Procesos constructivos a través de la mediación escolar

Recebido: 23/07/2021 | Revisado: 28/07/2021 | Aceito: 29/07/2021 | Publicado: 05/08/2021

Lúcia Maciel Couto
ORCID: https://orcid.org/0000-0002-3957-260X
Universidade de Cuiabá, Brasil
E-mail: luciadancemaciel@hotmail.com
Edenar Souza Monteiro
ORCID: https://orcid.org/0000-0002-9666-7920
Universidade de Cuiabá, Brasil
E-mail: edenar.m@gmail.com
Marcela Cristiane Ribeiro Brito
ORCID: https://orcid.org/0000-0002-2491-2106
Universidade de Cuiabá, Brasil
E-mail: marcelacrbrito@gmail.com
Monica Vieira da Silva
ORCID: https://orcid.org/0000-0003-0828-2236
Universidade de Cuiabá, Brasil
E-mail: monicaconq@hotmail.com

\begin{abstract}
Resumo
O texto objetivou estudar a convivência escolar, suas violências, conflitos e a mediação no espaço e tempo da escola, utilizando-se de ferramentas pedagógicas e metodológicas que visem exercitar a empatia, o diálogo e a resolução de conflitos, demonstrando de que maneira as Práticas Restaurativas, por meio da Mediação, podem auxiliar na melhoria do ensino aprendizagem no universo escolar. A metodologia foi desenvolvida via revisões bibliográficas utilizando como método dialético em uma abordagem etnográfica (Marconi; Lakatos, 2005), que buscou aporte teórico em autores como: Abramoway (2002), Heredia (1999), Marshal (2019). Os resultados apontaram que as Práticas Restaurativas, por meio da Mediação de Conflitos, Círculos Restaurativos, Comunicação Não Violenta são ferramentas que promovem aos indivíduos uma ressignificação e reconstrução na maneira de ensino aprendizagem dentro e fora do espaço escolar. Palavras-chave: Mediação escolar; Convivência educacional; Violência; Conflito.
\end{abstract}

\begin{abstract}
The text aimed to study the school life, its violence, conflicts and mediation in the space and time of the school, using pedagogical and methodological tools that aim to exercise empathy, dialogue and conflict resolution, demonstrating how the Practices Restorative, through Mediation, can help to improve teaching and learning in the school universe. The methodology was developed through bibliographic reviews using a dialectical method in an ethnographic approach (Marconi; Lakatos, 2005), which sought theoretical support in authors such as: Abramoway (2002), Heredia (1999), Marshal (2019). The results showed that Restorative Practices, through the Mediation of Conflicts, Restorative Circles, Non-Violent Communication are tools that promote individuals to a new meaning and reconstruction in the way of teaching and learning inside and outside the school space.
\end{abstract}

Keywords: School mediation; Educational coexistence; Violence; Conflict.

\section{Resumen}

El texto tuvo como objetivo estudiar la vida escolar, su violencia, los conflictos y la mediación en el espacio y tiempo de la escuela, utilizando herramientas pedagógicas y metodológicas que tienen como objetivo el ejercicio de la empatía, el diálogo y la resolución de conflictos, demostrando cómo las Prácticas Restaurativas, a través de la Mediación, pueden ayudar a mejorar la enseñanza y el aprendizaje en el universo escolar. La metodología se desarrolló a través de revisiones bibliográficas utilizando un método dialéctico en un enfoque etnográfico (Marconi; Lakatos, 2005), que buscó apoyo teórico en autores como: Abramoway (2002), Heredia (1999), Marshal (2019). Los resultados mostraron que las Prácticas Restaurativas, a través de la Mediación de Conflictos, Círculos Restaurativos, Comunicación No Violenta son 
herramientas que promueven a los individuos a un nuevo significado y reconstrucción en la forma de enseñar y aprender dentro y fuera del espacio escolar.

Palabras clave: Mediación escolar; Convivencia educativa; Violencia; Conflicto.

\section{Introdução}

O texto teve como proposta estudar a convivência escolar, a violência, os conflitos e a mediação no espaço e tempo da escola, utilizando-se de ferramentas pedagógicas e metodológicas, que visem exercitar a empatia, o diálogo e a resolução de conflitos, demonstrando de que maneira as práticas restaurativas, por meio da mediação, podem auxiliar na melhoria do ensino aprendizagem no universo escolar.

Em relação aos conflitos no ambiente escolar, o Conselho Nacional de CNMP, (2014), aponta que existe um número expressivo de conflitos e muitos advém da falta do diálogo e empatia nos ambientes de convivência social. Tais conflitos promovem um espaço hostil, agressivo e pouco produtivo na comunidade escolar, causando violências psicológicas, sociais e físicas. O diálogo entre os profissionais da educação, estudantes e familiares geram um espaço harmonioso e propício para uma cultura de paz.

Quando ocorre o conflito, imediatamente tenta-se achar o culpado e, consequentemente, logo vem os julgamentos. O diálogo imediatamente desaparece, no entanto, se pararmos para ouvir atentamente as partes, na busca de compreender e atender as necessidades mútuas, utilizando-se as ferramentas corretas de forma construtiva, provavelmente teremos uma resolução para o conflito e as partes serão contempladas com a reflexão e o aprendizado sobre o ocorrido.

Segundo Morrison, (2005), existem maneiras educativas e construtivas para diminuir os conflitos escolares e promover mudanças, mas para que isso ocorra é necessário que a comunidade escolar esteja aberta à ampliar o olhar para além, repensando os pensamentos e ações perante si mesmo e o outro. O uso das práticas restaurativas, como mediação, círculos, comunicação não violenta, entre outras, no ensino aprendizagem trará um crescimento educacional e consequentemente uma diminuição da violência na comunidade escolar.

Nesse sentido, a utilização das práticas em espaços escolares, podem trazer resultados significativos e positivos, pois além de solucionar ou evitar conflitos, promove a restauração dos vínculos afetivos, de forma a "desenvolver as habilidades de escutar de forma ativa, de criar empatia e compreender as perspectivas, a cooperação, a negociação e a percepção da diversidade" (Morrison, 2005, p. 307).

Faz-se necessária a busca por uma ressignificação da identidade dos profissionais da educação em situações de conflito e violência, que poderá ser reconstruída por meio das práticas restaurativas, a exemplo da mediação de conflitos escolares, por acreditar que o universo escolar é marcante de convivência, espaço e encontro. Para realizar, no plano político educacional, os ensinos aprendizagens, em seu aspecto formal, bem como a educação socioemocional que se referem ao processo de entendimento e manejo de valores, tais como: solidariedade, amizade, responsabilidade, colaboração, empatia, organização, ética, cidadania honestidade, emoções e pela tomada de decisões responsáveis.

Tais elementos, tão desejáveis nas relações das convivências humanas e cada vez mais requisitados e necessários nos dias de hoje, deverão ser ensinados, praticados, estimuladas no universo escolar. É como afirmam as novas diretrizes da Base Nacional Comum Curricular (BNCC, 2017. p.10).

Nas escolas, as práticas restaurativas têm sido usadas para lidar com a gama de conflitos escolares, desde os mais simples até os mais complexos. No Brasil, diversas redes municipais e estaduais de ensino têm incentivado a sua implantação e ampliação, a exemplo da Secretaria do Estado de Educação de Mato Grosso - SEDUC/MT, que por meio do Projeto de Mediação de Conflito Escolar (o qual esta pesquisadora está presente na equipe), realiza em parceria com o Ministério Público (MPMT) e Tribunal de Justiça (TJMT), um trabalho de atendimento/acolhimento às unidades escolares do estado, na busca de minimizar as violências escolares promovendo a mudança dos conflitos discorridos na comunidade escolar, buscando a mudança do 
negativo, destrutivo para um conflito construtivo, pacífico e positivo, por meio de sessões de mediação escolar/familiar, palestras e cursos de orientação sobre as práticas restaurativas que envolvem o projeto.

Vivemos em um momento na história em que a sociedade desvaloriza as regras de boa convivência, o indivíduo assiste e vivencia isso de forma clara no seu cotidiano. Entende-se que na temática em questão devem ser considerados diversos fatores sociais, e a escola é chamada ao desafio de oferecer à comunidade escolar os exemplos de relações de afeto que envolvam a todos, promovendo aprendizagens nos conflitos e mudanças nos comportamentos.

A partir disso, surgiu o interesse em aprofundar os estudos nas práticas restaurativas, desafiando os padrões punitivos, encarando os conflitos como oportunidade de mudança e aprendizagem, promovendo o fortalecimento do indivíduo, ressaltando os valores da inclusão, pertencimento e solidariedade, levando os envolvidos a uma abordagem inclusiva e colaborativa, que resgata o diálogo, escuta ativa, a conexão com o próximo e comunicação entre os atores escolares e familiares.

As manifestações de conflitos em sala de aula e na hora dos intervalos, causam transtornos, falta de atenção, desinteresse tanto dos estudantes quanto dos profissionais da educação e por consequência, apresenta uma baixa no ensino e aprendizagem escolar.

Essa pesquisa propõe apresentar ferramentas para se facilitar a resolução dos conflitos de forma construtiva e positiva, dentro da comunidade escolar, através das práticas restaurativas por meio das técnicas da mediação de conflito, círculos restaurativos e comunicação não violenta, em favor da construção de uma cultura de paz.

A utilização das práticas restaurativas citadas anteriormente, são de grande importância, pois o indivíduo pode construir e reconstruir novas maneiras de conduzir seus conflitos, pensamentos, palavras e ações. São resultados palpáveis que promovem a empatia e autoempatia, na busca da cocriação do ser humano aberto ao diálogo, à escuta ativa, atendendo às suas necessidades e aceitando o outro sem julgamentos ou preconceitos.

Durante a jornada de trabalho desta pesquisadora como profissional da educação, foi possível que se vivenciassem muitos cargos promovidos pela educação, dentre eles: a docência, a Coordenação Pedagógica, Diretora substituta, Presidente do CDCE e Líder do Núcleo de Mediação Escolar da SEDUC, caminhos esses que possibilitaram-na galgar degraus de crescimento profissional e pessoal, onde estudos, vivências escolares e pessoais, levaram ao objeto dessa pesquisa, por acreditar que as práticas restaurativas por meio da mediação escolar, podem trazer bons resultados e proporcionar o conhecimento de ferramentas e técnicas para a ressignificação e reconstrução das formas de ensino aprendizagem atuantes no universo escolar.

Esta pesquisadora está lotada na Escola Estadual Presidente Médici como professora efetiva da disciplina de educação física no município de Cuiabá/MT, porém atua na sede da Secretaria de Educação de Mato Grosso - SEDUC/MT no Núcleo de Mediação Escolar desde 2019, onde participou da formação em Mediação Escolar e Familiar pelo Ministério Público e Tribunal de Justiça do Estado de Mato Grosso, aprofundando os estudos em Justiça Restaurativa, Comunicação não Violenta, Facilitador de Círculos e iniciação em Constelação familiar.

Atuar como mediadora de conflitos, proporcionou à pesquisadora uma ampliação do olhar para além do que já visto, ter o conhecimento das ferramentas que tangem as práticas restaurativas, propiciou a compreensão de como é possível fazer, ser e estar educação dentro do universo escolar e também a melhorar a qualidade de vida pessoal, por meio de uma cultura de paz, do diálogo, da escuta ativa e comunicação não violenta.

Mediar um conflito permite não apenas resolver um problema/ situação conflituosa, mas possibilitar aos envolvidos um crescimento pessoal e a busca de um olhar positivo e construtivo sobre tal situação em que, pode-se entender os pontos de vistas, analisar as vertentes e promover o crescimento pessoal e profissional do indivíduo. Quando mediamos um conflito buscamos o entendimento das partes e cocriamos um movimento harmonioso em conjunto, que reverbera em todo seu entorno, motivando a querer levar os conhecimentos a outros grupos de profissionais nas escolas, espera-se que essa pesquisa possa motivar outros profissionais e estudantes, propiciando tal crescimento pessoal e profissional a cada indivíduo que tiver acesso a ela. 
Ao pensarmos no ambiente escolar de maneira segura, restaurativa e protetiva, se faz necessário construir e fortalecer a escola, cocriando formas de gerenciar positivamente os conflitos permitindo alcançar esses objetivos.

O (CNMP, 2014, p.62), nos apresenta algumas ações importantes para a construção desse espaço mais seguro e pacifico:

1. um aprimorar, fortalecer e priorizar a boa conexão entre escola família comunidade, principalmente com o fortalecimento dos conselhos escolares e com uma maior participação dos pais no espaço escolar;

2. realizar atividades contínuas que possam melhorar o vínculo interno nas unidades escolares e tornar pacíficos os ambientes escolares, sobretudo com fortalecimento dos grêmios estudantis, dos conselhos escolares e de classe;

3. construir coletivamente as regras da convivência escolar, através de círculo de diálogos ou assembleias;

4. democratizar a escola e tornar democráticos os espaços do sistema escolar;

5. fortalecer a cidadania e a participação nas atividades escolares, construindo canais que permitam o protagonista de todos;

6. aprimorar o vínculo interno nas relações humanas, prioriza ando o diálogo e a cooperação entre todas as pessoas da comunidade escolar;

7. aperfeiçoar competências e habilidades que permitam uma boa comunicação é um bom diálogo entre todos;

8. construir soluções alternativas e pacificas aos conflitos, para que não termine em violência;

9. construção de conteúdos e atividades pedagógicas que sejam contexto alisados e façam sentido para os alunos;

10. criar redes informais de apoio à criança e adolescentes em situação de vulnerabilidade e manter uma boa articulação com a rede intersetorial de atendimento da escola, a escola também é parte.

Pensando nesse sentido de espaço educacional harmonioso e seguro, trago a referência e o norte da escola, o Plano Político Pedagógico - PPP, que tem como objetivo dar base aos planejamentos escolares, traçando as metas e ideais, em busca dos resultados permeados na construção coletiva da comunidade escolar, onde pensam, planejam, executam e avaliam os pontos positivos e negativos do trabalho educacional.

Buscando a projeção do futuro por meio do projeto, seus planos e propostas de ações, seguindo uma direção política, um eixo, segundo Gadotti, 1998, p.16), "Não se constrói um projeto sem uma direção política, um norte, um rumo" e sistematizando as atividades e projetos educacionais que definem o pedagógico do ensino aprendizagem, no que define o ser e realizar da escola.

Pensando no processo pedagógico, o ser humano deve partir do processo de construção por si próprio, pois conforme (FREIRE, 2005), a humanização parte do indivíduo e suas aceitações, obtendo a compreensão dos seus conflitos centrais.

Freire entende que, reconhecendo a presença histórica da desumanização, essa não é a vocação dos homens, pois se assim fosse, não haveria necessidade e nem possibilidade de se pensar a educação dos homens. Mas, pelo contrário, ele entende que a vocação do ser humano é a busca de sua própria humanização: a busca do "ser mais", isto é: "o objetivo básico de sua busca, que é o ser mais, a humanização, apresenta-se-lhe como um imperativo que deve ser existencializado" (FREIRE, 1969, p. 127).

Segundo Pacheco (2004), existem muitas críticas e descontentamentos com o modelo hegemônico escolar que nos é oferecido existem há um tempo. Mas o intrigante é como ainda existem tantas instituições com um modelo educacional similar ao de dois séculos atrás, mesmo com a ineficácia comprovada de certos métodos, o alto índice de evasão e desinteresse dos alunos, a escola continua da mesma forma. Ele faz menção ao modelo convencional escolar hegemônico, como um retrocesso, que tornam duradouro o velho paradigma escolar, reprodutor de oprimidos e opressores.

Nesse sentido, José Pacheco relata as escolas como confusas, que em um momento tornam o professor o centro do conhecimento, depois que o aluno é o centro, sendo que, o que realmente deve ser considerado na educação para e obter um bom ensino aprendizagem, são as relações, a comunicação, o vínculo entre a comunidade escolar, isto é centro.

$\mathrm{Na}$ busca das alternativas de resoluções dos conflitos, a ideia principal é a reaproximação, a recaptura dos valores, um encontro entre as pessoas, identificação das emoções, dos sentimentos, dos relacionamentos e das razões reais que geram os conflitos. 
A procura do encontro, que vem do latin, in contrary, significa encontro com meu oposto, busca o encontro com o eu, com o outro, com a transformação, com a ressignificação, com a sociedade, entre outros, segundo Moreno, (1996), estamos sempre a procura de, ao encontro de, então procuramos esse encontro para enfrentar o maior opressor seja ele, interno e externo, para solucionar, dissolver os conflitos e lidar com nossos medos ou temores.

Para elucidar como algumas ferramentas/métodos podem ser utilizados para se alcançar esses objetivos, este capítulo apresenta o referencial teórico que dialogou com a pesquisa e autores que discutem sobre as Práticas Restaurativas, suas abordagens e documentos que dialogam sobre a construção de uma cultura de paz nas unidades escolares, bem como outras nuances relevantes apresentados nas falas dos participantes da pesquisa.

\section{Metodologia}

A metodologia consistiu em uma pesquisa com abordagem qualitativa Bogdan e Biklen, (1994), de natureza descritiva e interpretativa Furasté, (2008), utilizando como método dialético em uma abordagem etnográfica e estudo de caso, quanto ao procedimento de coleta de dados, se fará por meio de questionário semiestruturado, com perguntas abertas e fechadas, entrevista gravadas e transcritas, realizadas em 10 unidades escolares do município de Cuiabá/MT, onde os participantes da pesquisa foram 10 profissionais da educação (sendo 05 Gestores e 05 professores), certificados em Mediação de Conflitos Escolar e Familiar, pelo Projeto de Mediação de Conflito Escolar ofertado pelo Tribunal de Justiça e Ministério Público em parceria com a SEDUC/MT, nos anos de 2018 e 2019.

\section{Resultados e Discussão}

Acreditamos que todo conflito pode e deve ser confrontado, porém de forma construtiva e pacífica. "Os conflitos fazem partes da natureza humana, sejam eles simples ou graves, devem ser vistos como oportunidade de mudanças e crescimento". (CNMP, 2014, p. 09). Eles estão presentes no contexto escolar, que são lugares privilegiados para a disseminação de valores e construção do conhecimento, que busca a educação integral do indivíduo nas suas competências gerais, cognitivas, acadêmicas, intelectuais, físicas e sociais. Por isso devemos apresentar ferramentas, estratégias e habilidades para que possibilitem o gerenciamento pacífico dos conflitos. A temática sobre a violência escolar, se refere a esses tipos de violências como consequências de um processo que começaria principalmente pelas desigualdades sociais, pela influência da mídia e pela desestruturação familiar, pela falta de limites e valores humanos, referências de adolescentes que tem continuidade nos grupos comunitários e relações sociais pertencentes ao ambiente externo à escola.

Aparecem também, nos estudos realizados sobre a violência escolar, as causas socioeconômicas, a exclusão social, ou melhor, a falta de acesso, o tráfico de drogas, a falta de oportunidades e de trabalho, o rápido crescimento biológico, o tempo livre e ocioso, a falta de perspectivas, falta de um sonho, embasando em um contexto histórico, social e cultural, decorrente das oportunidades, situações e ações que diferem os indivíduos. A mediação na escola não compreende somente a resolução de conflitos, mas também a prevenção. Assim, é fundamental a sensibilização de todos para a inclusão e compreensão do processo de mediação no universo escolar, visto que, essa ferramenta representa mais do que uma simples técnica, indica um processo educativo e pedagógico, isto é, um novo olhar para compreender a problemática que circunda o ambiente escolar, promovendo a cultura de paz.

\section{Considerações Finais}

Esta pesquisa foi realizada em dez unidades escolares estaduais do município de Cuiabá/MT, onde obteve como participantes, cinco gestores e cinco professores, todos servidores efetivos formados no curso de Mediação de Conflitos Escolar 
e Familiar ofertado pelo TJ/MP/SEDUC, que trouxe diálogos sobre as Práticas Restaurativas como ferramentas para auxiliar na melhoria do ensino aprendizagem no espaço escolar.

Buscou-se fazer referência às Práticas Restaurativas por meio da Mediação de conflitos, os Círculos Restaurativos e a Comunicação não violenta, como ferramentas/ métodos para promover a mudança na construção do ensino aprendizagem dos profissionais da educação, bem como propiciar um espaço educacional mais pacífico e harmonioso para a comunidade escolar.

Para trabalhos futuros pensamos em levar esta prática da mediação de conflitos para as salas de formação continuada, possibilitando assim mais ensino e aprendizagem os profissionais da educação, no auxílio das intercorrências ed ucacionais diárias.

\section{Referências}

Abramoway, M. \& Rua, M. G. (2002). Violências nas escolas. UNESCO no Brasil.

Badini, L. L. M. \& Borges V.M.G. (2015). Citado no Manual de Negociação e Mediação para Membros do Ministério Público. (2a ed.) CNMP.

Brasil. (2018). Base Nacional Comum Curricular: Ensino Médio. MEC/Secretaria de Educação Básica.

Brasil. (2004). Ministério da Educação. Assessoria de Comunicação Social. Estatuto da Criança e do Adolescente. MEC.

Brito, C.H. (2007). A mediação como instrumento de integração e pacificação na escola. In: Lima, F.A., Fagundes, R.V., Pinto, V.L. Manual de Mediação: teoria e prática. New Hampton Press.

Charlot, B. (2002). Tradução de Sonia Taborda. A violência na escola: como os sociólogos franceses abordam a questão. In: Sociologias, Porto Alegre, v. 4, $\mathrm{n}$. $8, \mathrm{jul} / \mathrm{dez}$.

Chauí, M. (2005). Cultura e democracia. (11a ed.) Cortez Editora.

Dias, D. O. K. (2012). Bullying - violência entre pares no contexto escolar. Citada no livro Psicologia na Prática Jurídica A Criança em foco. São Paulo, SP: Editora Saraiva.

Fante, C. A. Z. (2005). Fenômeno bullying: como prevenir a violência nas escolas e educar para a paz. Versus Editora.

Fernandes, P. (2017). Meios Consensuais de Resolução de Conflitos no Novo Código de Processo Civil: A Conciliação e a Mediação. Jus.com.br/artigos/59938.

Heredia, R. A. S. (1999). Enfoque global de la escuela como marco de aplicacion de los programas de resolución de conflictos. In: Medicaión escolar propuestas, reflexiones y experiencias. Florencia Brandoni (Comp.). Buenos Aires, Barcelona, México: Paidos.

Rosenberg, M. B. (2019). A linguagem da paz em um mundo de conflitos: sua próxima fala mudará seu mundo. Tradução Grace Patricia Close Deckers. Palas Athena.

Michaud, Y. (1986). A violência. Ática.

Miranda N. \& Gama F. \& Meirelles, D. R. S. (2012). Mediação judicial no projeto do novo Código de Processo Civil. Revista de Arbitragem e Mediação, São Paulo: RT, n. 33 .

Odalia, N. (2004). O que é violência. Editora Brasiliense.

Olweus citado por Dias, D. O. k.(2012). Bullying - violência entre pares no contexto escolar. Citada no livro Psicologia na Prática Jurídica - A Criança em foco. São Paulo, SP: Editora Saraiva.

Pimenta, C. A. M. \& Incrocci, L. M. M. C. (2018) O lugar dos processos de mediação e resolução de conflitos escolares: como nos vemos? Revista Eletrônica Científica Ensino Interdisciplinar Mossoró, 4(10)

Sales, L. M. M. \& Alencar E. (2007). Mediação de Conflitos: família, escola e comunidade. Conceito Editorial.

Schbbel, P. D. C. (2002). Mediação escolar entre pares: Semeando a paz entre os jovens. Willis Harmann House.

Vasconcelos, C. E. (2012) Mediação de conflitos e práticas restaurativas. (2a ed.), Método.

Warat, L. A. (2001). O Ofício do Mediador. Habitus. 